\title{
EVALUASI KEBERHASILAN TANAMAN REVEGETASI LAHAN PASCA TAMBANG BATUBARA PADA BLOK M1W PT JORONG BARUTAMA GRESTON, KALIMANTAN SELATAN
}

\author{
The Evaluation of the Success of Plant Revegetation in Post Coal Mining Block M1W PT \\ Jorong Barutama Greston, South Kalimantan
}

Omo Rusdiana ${ }^{*}$ dan Adi Setiadi $^{1}$

(Diterima Februari 2018/Disetujui September 2019)

\begin{abstract}
Reclamation activities should be carried out after mining operation for restoring and improving the function of the land to be in better condition and productive (P.60/Menhut-II/2009). This research aims to analyze the status of the success of revegetation, based on growth ability and performance of A. mangium plants at PT Jorong Barutama Greston Block MIW; to recommend improvements for the land and plants; and to identify the cause of revegetation failure. The results of this research indicated that status of the revegetation success at Block MIW have not been categorized as successful category. The success rate were considered from the average growth percentage and health level of plants which were less than $60 \%$ (score 1, bad performance), namely $59.38 \%$ and $50.01 \%$ respectively. The improvement that could be done were soil amendment and the use of plants which are resistant to poor environment. The plants have to be resistant to acid soil and high content of heavy metal. The main causes of revegetation failure were site condition which were not conducive for A. mangium plant growth and lack of plant maintenance. This was the cause of bad plant growth performance. Besides that, Standard Operational Procedure (SOP) on revegetation activities need to be improved and plant maintenance should be enhanced, particularly those related with pest and disease control.
\end{abstract}

Key words: A. mangium, evaluation, post coal mining, revegetation

\section{PENDAHULUAN}

Pertambangan adalah sebagian atau seluruh tahapan kegiatan dalam rangka penelitian, pengelolaan, dan pengusahaan mineral atau batu bara yang meliputi penyelidikan umum, eksploitasi, studi kelayakan, konstruksi, penambangan, pengelolaan dan pemurnian, pengangkutan, dan penjualan serta kegiatan pasca tambang (Kemenhut 2011). PT Jorong Barutama Greston (PT JBG) merupakan salah satu perusahaan pertambangan batubara yang terletak di Desa Swarangan, Kecamatan Jorong, Kabupaten Tanah Laut, Kalimantan Selatan. Kegiatan penambangan yang dilakukan oleh PT JBG merupakan penambangan terbuka (open pit mining), dimana untuk mendapatkan bahan tambang berupa batu bara, seluruh tanaman yang ada dipermukaan tanah dibersihkan, tanah dan batuan penutup dipindahkan ke suatu tempat sehingga mengakibatkan lahan terdegradasi, tidak produktif dan menjadi marjinal. Guna memperbaiki dan mengembalikan fungsi lahan ke kondisi yang lebih baik dan produktif perlu dilakukan kegiatan reklamasi sesuai peraturan yang telah dikeluarkan oleh Kementerian Kehutanan (P.4/Menhut-II/2011) dan Kementerian Energi dan Sumberdaya Mineral (Permen ESDM No. 18

\footnotetext{
${ }^{1}$ Departemen Silvikultur, Fakultas Kehutanan Institut Pertanian Bogor

* Penulis koresponden:

E-mail: orusdiana@yahoo.com
}

Tahun 2008).

Berdasarkan Peraturan Menteri Kehutanan Republik Indonesia No. P.60/Menhut-II/2009 tahun 2009 tentang Pedoman Penilaian Keberhasilan Reklamasi Hutan, kegiatan reklamasi meliputi penataan lahan, pengendalian erosi dan sedimentasi, serta revegetasi. Kegiatan revegetasi yang dilakukan perusahaan pertambangan di Indonesia seringkali tidak berhasil, hal tersebut dikarenakan kondisi lahan yang sangat marjinal, kurangnya ketersediaan top soil, adanya materi logam berat yang tersisa, dan keberadaan air asam tambang.

Berdasarkan latar belakang tersebut dilakukan penelitian yang bertujuan untuk menganalisis status keberhasilan revegetasi yang telah dilakukan oleh PT JBG. Selain itu, penelitian ini bertujuan memberikan rekomendasi perbaikan lahan dan tanaman, dan mengidentifikasi penyebab ketidakberhasilan revegetasi.

\section{METODE PENELITIAN}

\section{Waktu dan Lokasi Penelitian}

Penelitian ini dilaksanakan di perusahaan pertambangan batubara PT Jorong Barutama Greston, Kalimantan Selatan, yaitu pada areal revegetasi Blok M1W dengan luas 33.46 ha. Penelitian dilaksanakan selama 3 bulan pada tanggal 16 Februari - 30 Mei 2015 . 


\section{Alat dan Bahan}

Alat yang digunakan dalam penelitian ini yaitu alat tulis, kamera, kaliper, walking stick, laptop, software ArcGIS version 9.3, Global Mapper 13, SPSS 16.0, tally sheet, kalkulator, meteran, tali rafia, golok, GPS, dan kompas. Bahan yang digunakan dalam penelitian ini yaitu peta reklamasi dan rehabilitasi dengan skala 1:10000, dokumen AMDAL PT Jorong Barutama Greston, dan dokumen rencana serta realisasi reklamasi.

\section{Pembuatan Plot Contoh}

Plot contoh pengamatan yaitu Blok M1W dengan luas 33.46 ha. Penentuan plot contoh dilakukan dengan metode Systematic Sampling with Random Start serta menggunakan intensitas sampling sebesar 5\% (Kemenhut 2009), sehingga jumlah plot contoh pada Blok M1W sebanyak 17 plot dengan ukuran 40 m x 25 m (0.1 Ha). Sebaran plot contoh di peta dan sebaran tanaman dalam plot pengamatan di lapangan disajikan pada Gambar 1 dan Gambar 2.

\section{Pengambilan Data Tanaman}

Semua tanaman yang terdapat dalam plot ukuran 40 $\mathrm{m} \times 25 \mathrm{~m}$, diukur untuk memperoleh data tanaman. Data yang diambil adalah tinggi, diameter batang, diameter tajuk, dan kesehatan tanaman. Pengukuran diameter tanaman dilakukan pada titik $15 \mathrm{~cm}$ dari pangkal batang menggunakan kaliper manual, pengukuran diameter tajuk tanaman dilakukan dengan mengukur tajuk terpanjang dan terlebar dengan menggunakan meteran, sedangkan pengukuran tinggi dilakukan dengan menggunakan meteran dan walking stick. Pengamatan terhadap kondisi fisik tanaman juga dilakukan untuk mengetahui status kesehatan tanaman revegetasi.

\section{Persentase Tumbuh Tanaman}

Nilai persentase tumbuh tanaman dihitung dengan persamaan:

$$
\mathrm{T}=\frac{\sum h i}{\sum N i} \mathrm{x} 100 \%
$$

keterangan:

$$
\begin{aligned}
\mathrm{T} & =\text { persen tumbuh tanaman }(\%) \\
\mathrm{hi} & =\text { jumlah tanaman yang hidup plot ke-i } \\
\mathrm{Ni} & =\text { jumlah tanaman yang ditanam plot ke-i }
\end{aligned}
$$

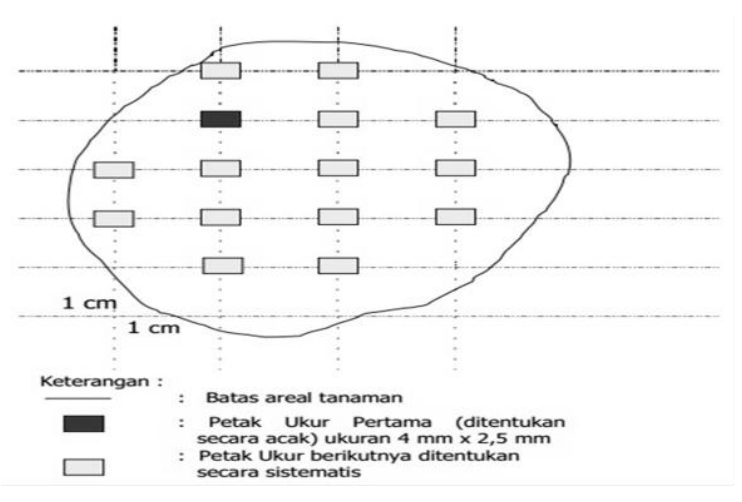

Gambar 1 Sebaran plot contoh di peta
Sementara rata-rata persentase tumbuh tanaman dihitung dengan persamaan sebagai berikut:

$$
\mathrm{R}=\sum_{i=1}^{n} T i / n
$$

keterangan:

$\mathrm{R}=$ rata-rata persentase tumbuh tanaman (\%)

$\mathrm{Ti}=$ jumlah persentase tumbuh tanaman plot ke-i

$\mathrm{n} \quad=$ jumlah seluruh plot

\section{Persentase Kesehatan Tanaman}

Nilai persentase kesehatan tanaman dihitung dengan persamaan:

$$
\mathrm{K}=\frac{\sum r i}{\sum h i} x 100 \%
$$

keterangan:

$\mathrm{K}=$ persentase kesehatan tanaman $(\%)$

$\mathrm{ri}=$ jumlah tanaman sehat plot ke-i

hi $=$ jumlah tanaman yang hidup plot ke-i

Rata-rata persentase kesehatan tanaman dihitung dengan persamaan sebagai berikut:

$$
\mathrm{P}=\sum_{i=1}^{n} K i / n
$$

dimana:

$\mathrm{P}=$ rata - rata persentase kesehatan tanaman $(\%)$

$\mathrm{Ki}=$ jumlah persentase kesehatan tanaman plot ke-i

$\mathrm{n} \quad=$ jumlah seluruh plot

\section{Diameter Batang dan Tinggi Tanaman}

Persamaan untuk menghitung rata-rata tinggi dan diameter tanaman yaitu sebagai berikut:

$$
\mathrm{d}=\sum_{i=1}^{n} d i / n \quad \mathrm{t}=\sum_{i=1}^{n} t i / n
$$

keterangan:

$\mathrm{d} \quad=$ rata-rata diameter batang $(\mathrm{cm})$

$\mathrm{t} \quad=$ rata-rata tinggi $(\mathrm{cm})$

di = diameter pohon ke-i

ti = tinggi pohon ke-i

$\mathrm{n} \quad$ = jumlah pohon yang diukur

\section{Diameter Tajuk}

Persamaan untuk menghitung diameter tajuk tanaman yaitu sebagai berikut:

$$
\mathrm{dt}=\frac{t p+t l}{2}
$$

keterangan:

$$
\begin{aligned}
\mathrm{dt} & =\text { diameter tajuk }(\mathrm{cm}) \\
\mathrm{tp} & =\operatorname{tajuk} \text { terpanjang }(\mathrm{cm}) \\
\mathrm{tl} & =\text { tajuk terlebar }(\mathrm{cm})
\end{aligned}
$$

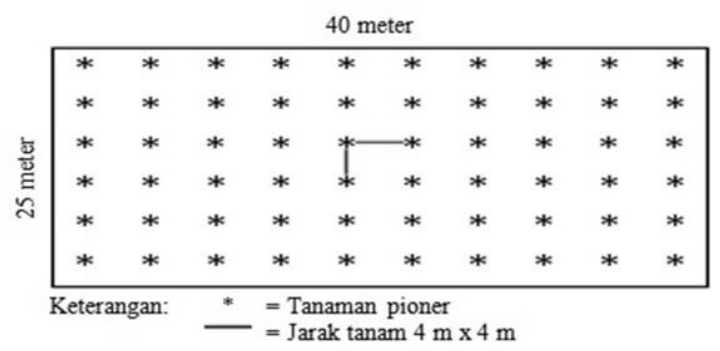

Gambar 2 Skema plot contoh di lapangan 
Rata-rata diameter tajuk dihitung dengan persamaan sebagai berikut:

keterangan:

$$
\mathrm{Rt}=\sum_{i=1}^{n} d t i / n
$$

$\mathrm{Rt}=$ rata-rata diameter tajuk $(\mathrm{cm})$

$\mathrm{dti}=$ jumlah diameter tajuk pohon ke-i

$\mathrm{n} \quad=$ jumlah pohon yang diukur

\section{Analisis Data}

Penelitian ini menggunakan analisis statistik deskriptif dengan tujuan untuk mengelompokkan atau mengklasifikasikan data pertumbuhan tanaman. Adapun tahapan analisis statistik data pada penelitian ini yaitu:

\section{Jangkauan (range)}

Range adalah selisih bilangan terbesar dan terkecil dari suatu kumpulan data. Rumus yang digunakan adalah:

$$
R=X \max -X \min
$$

Keterangan:

$\mathrm{R} \quad=$ jangkauan (range)

$\mathrm{X}_{\max }=$ nilai terbesar

$\mathrm{X}_{\min }=$ nilai terkecil

\section{Jumlah Kelas}

Jumlah kelas adalah pengelompokkan data pada interval tertentu yang dibagi dalam kelas. Rumus yang digunakan adalah:

$$
K=3.3 \log (\mathrm{n})+1
$$

Keterangan:

$$
\begin{array}{ll}
\mathrm{K} & =\text { jumlah kelas } \\
\mathrm{n} & =\text { banyaknya data }
\end{array}
$$

\section{Interval}

Interval adalah selang atau selisih dari data yang dikelompokkan berdasarkan kelas tertentu. Rumus yang

Tabel 1 Jumlah tanaman pada setiap plot pengamatan digunakan adalah:

$$
I=\frac{X \max -X \min }{K}
$$

Keterangan:

$\mathrm{I}=$ interval

$\mathrm{X}_{\max }=$ nilai terbesar

$\mathrm{X}_{\text {min }}=$ nilai terkecil

$\mathrm{K}$ = jumlah kelas

\section{Simpangan Baku (standart deviation)}

Standart deviation adalah rata-rata jarak penyimpangan titik-titik data diukur dari nilai nilai rata-rata data tersebut. Rumus yang digunakan adalah:

$$
S=\sqrt{\frac{\sum_{i=1}^{n}(x i-\bar{x}}{n}}
$$

Keterangan:

$$
\begin{array}{ll}
\mathrm{S} & =\text { simpangan baku } \\
\mathrm{xi} & =\text { nilai data ke- } \mathrm{i} \\
\bar{x} & =\text { rata }- \text { rata data }
\end{array}
$$

\section{HASIL DAN PEMBAHASAN}

\section{Persentase Tumbuh dan Pertumbuhan Tanaman}

Hasil pengamatan di lapangan menunjukkan bahwa di lokasi penelitian yang terbagi menjadi 17 plot contoh terdapat satu jenis tanaman yang ditemukan yaitu akasia (Acacia mangium) yang ditanam pada tahun 2013 yang berumur 2 tahun. Rekapitulasi jumlah tanaman yang diamati tersaji pada Tabel 1.

Setiap plot contoh pengamatan yang berukuran 0.1 ha maksimal terdapat 63 tanaman sehingga akan diketahui jumlah tanaman yang hidup dan jumlah tanaman yang mati. Rata-rata tanaman yang hidup pada plot pengamatan sebesar 374/ha dan rata-rata tanaman yang mati sebesar 256/ha. Rekapitulasi persen tumbuh setiap plot pengamatan disajikan pada Gambar 3 .

\begin{tabular}{cllccccc}
\hline \multirow{2}{*}{ Plot Ke- } & \multirow{2}{*}{ Jenis Tanaman } & \multirow{2}{*}{ Nama Ilmiah } & \multicolumn{2}{c}{ Daya Hidup } & \multicolumn{3}{c}{ Performa Tanaman } \\
\cline { 4 - 7 } & & Hidup & Mati & Sehat & Kurang Sehat & Merana \\
\hline 1 & Akasia & Acacia mangium & 40 & 23 & 23 & 7 & 10 \\
2 & Akasia & Acacia mangium & 30 & 33 & 19 & 5 & 6 \\
3 & Akasia & Acacia mangium & 46 & 17 & 1 & 27 & 18 \\
4 & Akasia & Acacia mangium & 52 & 11 & 31 & 15 & 6 \\
5 & Akasia & Acacia mangium & 45 & 18 & 23 & 14 & 8 \\
6 & Akasia & Acacia mangium & 28 & 35 & 17 & 10 & 1 \\
7 & Akasia & Acacia mangium & 48 & 15 & 12 & 24 & 10 \\
8 & Akasia & Acacia mangium & 30 & 33 & 21 & 8 & 1 \\
9 & Akasia & Acacia mangium & 18 & 45 & 8 & 2 & 8 \\
10 & Akasia & Acacia mangium & 38 & 25 & 28 & 3 & 2 \\
11 & Akasia & Acacia mangium & 24 & 39 & 3 & 3 & 18 \\
12 & Akasia & Acacia mangium & 42 & 21 & 25 & 16 & 1 \\
13 & Akasia & Acacia mangium & 49 & 14 & 38 & 11 & 0 \\
14 & Akasia & Acacia mangium & 18 & 45 & 9 & 10 & 12 \\
15 & Akasia & Acacia mangium & 58 & 5 & 36 & 15 & 7 \\
16 & Akasia & Acacia mangium & 37 & 26 & 12 & 13 & 12 \\
17 & Akasia & Acacia mangium & 33 & 30 & 16 & 15 & 2 \\
\hline Rata-rata/plot $(0.1$ ha) & & 371.4 & 25.6 & 18.9 & 11.9 & 7.2 \\
\hline Rata-rata/ha & & 374 & 256 & 189 & 119 & 72 \\
\hline
\end{tabular}


Nilai persen tumbuh diperoleh dengan membandingkan antara jumlah tanaman hidup dengan jumlah tanaman yang ditanam pada plot contoh. Rata-rata persen tumbuh pada plot pengamatan sebesar $59.38 \%$, nilai rata-rata yang diperoleh masih di bawah $80 \%$ sehingga dilihat dari rata-rata persen tumbuh tanaman status keberhasilan revegetasi masih dikatakan belum berhasil karena seharusnya nilai tersebut lebih dari $80 \%$ (Kemenhut 2009). Persen tumbuh tertinggi ditunjukkan pada Plot 15 sebesar $92.06 \%$ sedangkan terendah ditunjukkan pada Plot 14 dan Plot 9 sebesar $28.57 \%$. Rendahnya persen tumbuh tanaman dapat dikatakan bahwa kemampuan adaptasi tanaman A. mangium terhadap lokasi tempat tumbuh belum berjalan dengan baik. Hal ini disebabkan karena pada plot tersebut banyak tanaman yang mengalami kematian dibuktikan dengan adanya sisa ajir tanaman yang tidak tanaman A. mangium nya mati karena gangguan dari penggembalaan ternak liar.

Selain itu, faktor penyebab dari kematian A. mangium yaitu karena adanya aliran dan genangan air di luar saluran drainase yang telah dibuat. Aliran air ini terbentuk pada kondisi tanah yang mengalami pemadatan (Putri 2012). Hasil pengamatan di lapangan bahwa ketebalan top soil yang tipis juga berakibat tanah overburden yang muncul dipermukaan tanah sehingga pada saat terjadi hujan lapisan tanah top soil akan tergerus erosi dengan mudah.

Pertumbuhan tanaman hasil revegetasi pada setiap plot pengamatan dapat dilihat pada dimensi tanaman. Dimensi tanaman yang diamati pada penelitian ini

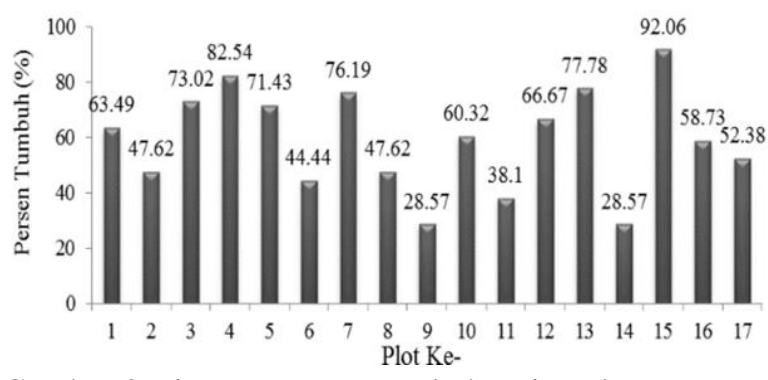

Gambar 3 Diagram persen tumbuh setiap plot pengamatan

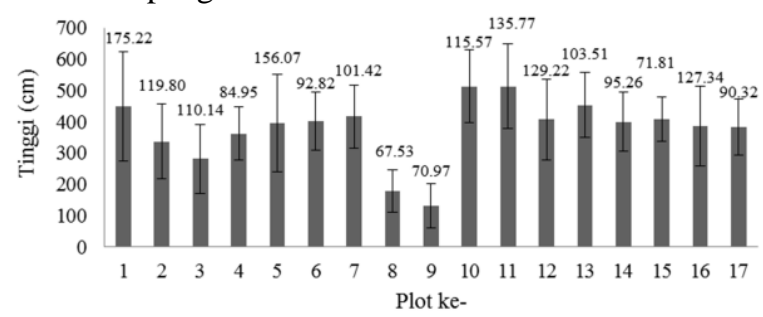

Gambar 4 Diagram rata-rata tinggi tanaman $A$.

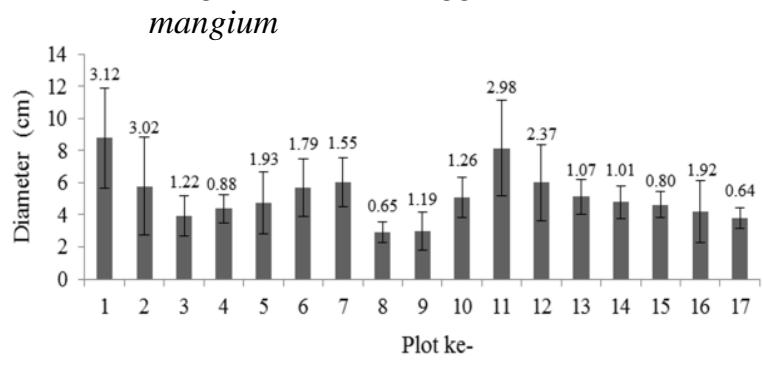

Gambar 5 Diagram rata-rata diameter tanaman $A$. mangium adalah tinggi, diameter batang, dan diameter tajuk. Rekapitulasi nilai rata-rata dan simpangan baku pada setiap parameter tersaji pada Gambar 4 dan 5 .

Berdasarkan pengambilan data tinggi, diameter batang, dan diameter tajuk pada masing-masing plot pengamatan diperoleh bahwa plot 10 dan 11 memiliki rata-rata tinggi tanaman yang tertinggi, yaitu sebesar $513.67 \mathrm{~cm}$ dan plot 9 memiliki rata-rata tinggi tanaman terendah, yaitu $131.22 \mathrm{~cm}$. Rata-rata diameter batang tertinggi terdapat pada plot 1 sebesar $8.77 \mathrm{~cm}$ dan plot 8 memiliki rata-rata diameter batang terendah sebesar $2.89 \mathrm{~cm}$. Rata-rata diameter tajuk tertinggi dan terendah masing-masing terdapat pada plot 1 dan plot 9 sebesar $269.21 \mathrm{~cm}$ dan $67.33 \mathrm{~cm}$. Nilai rata-rata pertumbuhan tinggi dan diameter di atas masih di bawah rata-rata pertumbuhan yang normal dengan umur tanaman sudah mencapai 2 tahun sehingga besarnya diameter tajuk pada tanaman A. mangium memiliki nilai yang rendah.

Menurut Krisnawati et al. (2007) pertumbuhan tinggi pada umur $2-3$ tahun dapat mencapai $10-15 \mathrm{~m}$ dan pertumbuhan diameter dapat mencapai $15 \mathrm{~cm}$. Hal ini menjelaskan bahwa pertumbuhan tanaman $A$.

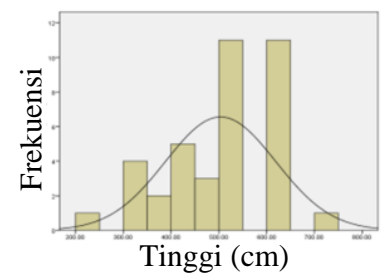

(a)

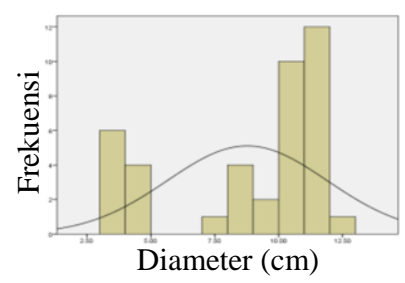

(b)

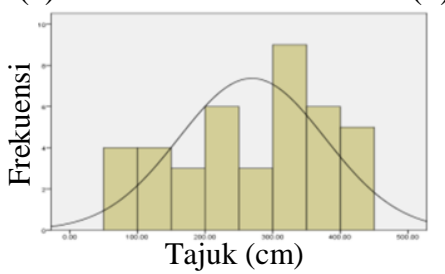

(c)

Gambar 7 Histogram nilai sebaran tertinggi pada (a) tinggi, (b) diameter, dan (c) diameter tajuk

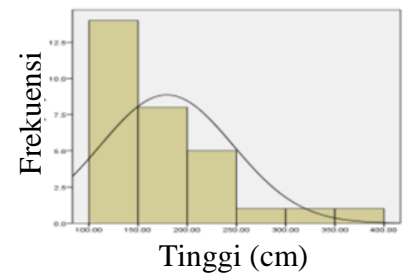

(a)

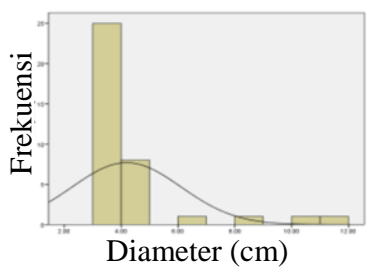

(b)

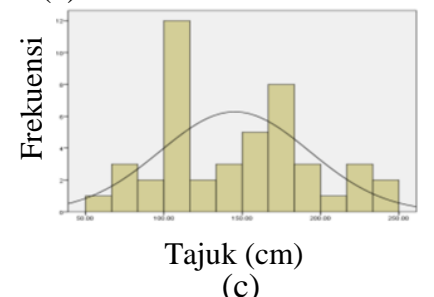

(c)

Gambar 8 Histogram nilai sebaran terendah pada (a) tinggi, (b) diameter, dan (c) diameter tajuk 
mangium di lokasi penelitian mengalami gangguan dan menyebabkan kurang optimalnya pertumbuhan tanaman pada areal tersebut.

Adanya nilai simpangan baku maka dapat diketahui sebaran data pada setiap plot pengamatan baik itu sebarang tinggi, diameter batang, dan diameter tajuk. Ukuran pemusatan dan penyebaran data dari setiap parameter pertumbuhan disajikan dalam bentuk histogram tersaji pada Gambar 7 dan 8.

Berdasarkan hasil statistik diperoleh bahwa sebaran data tanaman A. mangium di semua plot pengamatan bahwa nilai tertinggi (Gambar 7) memiliki tinggi 600 $650 \mathrm{~cm}$ sebesar $11 \%$ terdapat di plot 10 , diameter batang $11-12 \mathrm{~cm}$ sebesar $12 \%$ terdapat di plot 1 , dan diameter tajuk $300-350 \mathrm{~cm}$ sebesar $9 \%$ terdapat di plot 1, sedangkan nilai terendah (Gambar 8) dari seluruh plot pengamatan yang memiliki tinggi $100-150 \mathrm{~cm}$ sebesar $14 \%$ terdapat di plot 8 , diameter batang $3-4 \mathrm{~cm}$ sebesar $25 \%$ terdapat di plot 16 , diameter tajuk $100-$ $150 \mathrm{~cm}$ sebesar $12 \%$ terdapat di plot 5 . Tinggi rendahnya pertumbuhan tanaman A. mangium disebabkan faktor lingkungan yang kurang mendukung pertumbuhan tanaman dan kondisi tanah yang yang mengandung logam berat cukup tinggi yaitu unsur $\mathrm{Al}$ dan $\mathrm{pH}$ yang cukup masam sehingga mengganggu pertumbuhan tanaman. Pengujian statisitik untuk pertumbuhan tanaman A. mangium menggunakan selang kepercayaan pada taraf nyata $5 \%$ sehingga akan didapatkan kriteria kondisi pertumbuhan pada setiap plot pengamatan.

\section{Kesehatan Tanaman}

Kesehatan tanaman ditunjukkan dengan persentase kesehatan tanaman dan ada tidaknya gangguan tanaman. Rekapitulasi persentase kesehatan tanaman disajikan pada Gambar 9.

Nilai persentase tertinggi terdapat pada plot 13 sebesar $77.55 \%$ dan nilai persentase terendah terdapat pada plot 3 dengan nilai sebesar $2.17 \%$. Rata-rata persentase kesehatan tanaman pada plot pengamatan sebesar $50.01 \%$ nilai rata-rata yang diperoleh masih di bawah $60 \%$ (masuk dalam nilai skor 1) sehingga kondisi pertumbuhan tanaman dikategorikan tidak baik. Sama halnya dengan nilai persen tumbuh tanaman, persen kesehatan tanaman harus lebih dari $90 \%$ atau nilai skor 5 (Kemenhut 2009).

Rendahnya persentase kesehatan tanaman disebabkan karena tidak ada pemeliharaan dan pengendalian hama dan penyakit di lokasi penanaman kurang diperhatikan. Terbukti pada tanaman A. mangium di lokasi penelitian terdapat beberapa gangguan tanaman yang menghambat dari pertumbuhan dan perkembangan tanaman. Gejala yang ditampakkan tanaman karena kekurangan suatu unsur hara dapat menjadi petunjuk kasar dari fungsi unsur hara yang bersangkutan (Lakitan 2007). Berikut ini merupakan gejala atau tanda yang ditimbulkan dari gangguan tanaman A. mangium tersaji pada Tabel 2.

Gambar 10 menunjukkan bahwa gangguan tanaman A. mangium berupa serangan hama dan penyakit pada setiap plot pengamatan terlihat cukup tinggi. Secara keseluruhan yang mengalami gangguan tanaman tertinggi terdapat pada plot 12 dengan gejala tanaman berupa bercak hitam sebesar $47.37 \%$. Plot 11 memiliki persentase tertinggi yang menunjukkan gejala daun manguning sebesar $43.48 \%$. Gejala bercak hitam tertinggi terdapat pada plot 12 sebesar $47.37 \%$, plot 15 menunjukkan gejala mati cabang tertinggi sebesar $45.16 \%$, plot 15 terdapat $26.88 \%$ yang terserang hama pemakan daun, plot 8 memiliki kondisi tanaman kerdil atau stagnasi tertinggi sebesar $18.52 \%$, gejala rontok daun tertinggi terdapat pada plot 3 sebesar $15.32 \%$, kemudian plot 14 terdapat $21.21 \%$ yang terkena gejala daun keriting, plot 2 dengan gejala tanaman teringgi daun seperti terbakar sebesar $11.43 \%$, dan hanya pada plot 9 terdapat bejolan pada daun sebesar $25.93 \%$.

Tingginya persentase gangguan tanaman yang terjadi pada setiap plot pengamatan disebakan karena kurangnya pemeliharaan tanaman dan tidak adanya pengendalian hama dan penyakit setelah penanaman di lapangan. Keberadaan tanaman $A$. mangium yang terganggu kesehatannya akan merugikan pihak perusahaan karena akan menurunkan nilai persen kesehatan tanaman di lokasi penelitian.

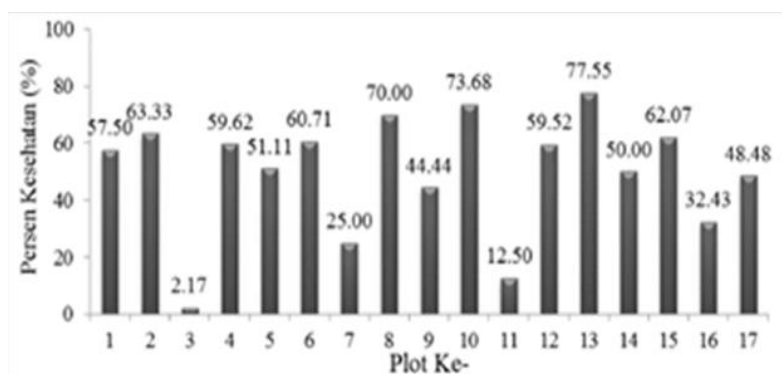

Gambar 9 Diagram persentase kesehatan tanaman pada setiap plot pengamatan

Tabel 2 Gangguan tanaman A. mangium di plot pengamatan

\begin{tabular}{|c|c|c|}
\hline No & Gangguan Tanaman & Gejala atau Tanda \\
\hline 1 & Mati cabang & $\begin{array}{l}\text { Percabangan tanaman mati dengan ditandai gugurnya daun pada ranting } \\
\text { pohon }\end{array}$ \\
\hline 2 & Daun seperti terbakar & Daun berubah berwarna hitam seperti terbakar \\
\hline 3 & Benjolan pada daun & Permukaan daun tampak melengkung dan membentuk benjolan \\
\hline 4 & Daun menguning & Daun berubah berwarna kuning seperti gejala nekrosis \\
\hline 5 & Rontok daun & Daun dimakan hama sampai habis dan menyisakan ranting \\
\hline 6 & Bercak hitam & Terdapat tepung hitam yang melekat pada daun \\
\hline 7 & Stagnasi/Kerdil & $\begin{array}{l}\text { Tinggi tanaman paling pendek dari tanaman lain pada tanaman yang } \\
\text { seumur }\end{array}$ \\
\hline 8 & Hama pemakan daun & Daun dimakan hama dengan ditandai bolong pada daun \\
\hline 9 & Daun keriting & Daun menggulung tampak seperti melilit \\
\hline
\end{tabular}




\section{Faktor Penyebab Ketidakberhasilan Revegetasi}

Faktor lingkungan yang dapat mempengaruhi pertumbuhan tanaman di antaranya yaitu suhu, kelembaban, iklim, curah hujan, dan tanah. Lahan pasca tambang memiliki karakteristik lahan dan kondisi lingkungan yang berbeda dengan tanah biasa (Setiadi 2012). Faktor lingkungan seperti kondisi tanah menjadi salah satu hambatan dalam pertumbuhan tanaman. Jika pertumbuhan tanaman terganggu maka tanaman akan meresponnya dengan memperlihatkan secara fisik dengan menunjukkan beberapa gejala seperti daun menguning, diameter batang yang kecil, yang mati cabang, dan stagnasi.

Kualitas tempat tumbuh merupakan gabungan dari banyak faktor lingkungan, misalnya jenis tanah, kedalaman tanah, tekstur tanah, karakteristik profil tanah, komposisi mineral, dan iklim mikro (Baker et al. 1979 dalam Lakitan 2007). Berdasarkan penelitian yang telah dilakukan Megawati (2014) di Blok M1W menunjukkan hasil analisis tanah yang memberikan beberapa gambaran permasalahan tempat tumbuh tanaman. Lokasi pengambilan sampel tanah terbagi dalam tiga kategori yaitu normal, sedang, dan buruk dengan kedalaman masing-masing $0-30 \mathrm{~cm}$ dan $30-$ $60 \mathrm{~cm}$. Permasalahan yang muncul dilokasi tersebut memiliki permasalahan pada tekstur tanah yang didominasi oleh pasir sebesar $62.54-85.75 \%$ dan $\mathrm{pH}$ yang masam berkisar 4.37 - 4.95 serta memiliki nilai KTK yang cukup rendah yaitu sebesar 11.83 me/100g. Kondisi berpasir tersebut disertai dengan kelarutan $\mathrm{Al}$ yang cukup tinggi hingga $1.01-2.08 \mathrm{me} / 100 \mathrm{~g}$.

Buruknya kondisi tempat tumbuh ini di perparah dengan kurangnya perbaikan lahan dan pemeliharaan tanaman sehingga hal ini menyebabkan ketidakberhasilan revegetasi pada lokasi tersebut. Hasil pengamatan di lapangan menunjukkan bahwa di lokasi penelitian hanya beberapa plot saja yang sudah dilakukan perbaikan lahan dan pemeliharaan tanaman, keterbatasan pekerja dan biaya yang besar menjadi kendala kurangnya dilakukannya tindakan tersebut. Pemeliharaan tanaman yang telah dilakukan oleh perusahaan berupa pemangkasan cabang (pruning) dan penyulaman dengan diikuti treatment pembenah tanah (soil amendment) yang disesuaikan dengan kondisi tanahnya. Perbaikan lahan yang telah dilakukan kaitannya dengan pembenah tanah adalah pengapuran, penggunaan bahan organik, serta pembuatan parit atau

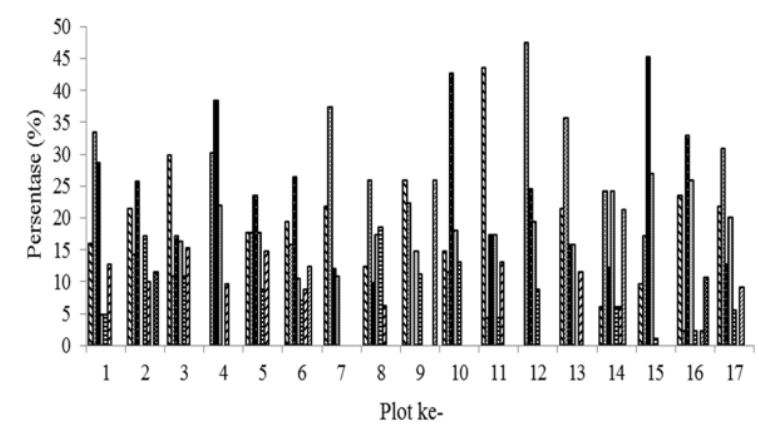

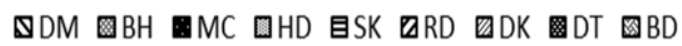

Gambar 10 Diagram persentase gangguan tanaman $A$. mangium saluran drainase untuk pengendali erosi dan sedimentasi.

Pengendalian hama dan penyakit juga tidak dilakukan setelah penanaman mengingat SOP mengenai kegiatan pemeliharaan tanaman tidak tercantum dalam SOP tersebut dan hanya terdapat tiga kegiatan yaitu pemupukkan, penyiangan, dan peyulaman. Hal tersebut menyebabkan pertumbuhan tanaman terganggu dan tidak dapat berkembang dengan optimal. Ketidaknormalan pertumbuhan tanaman akibat kurangnya pemeliharaan tanaman ini menjadi salah satu faktor penyebab rendahnya keberhasilan revegetasi.

\section{Rekomendasi Perbaikan Lahan dan Tanaman}

Penyebab utama ketidakberhasilan revegetasi di Blok M1W PT JBG yaitu kondisi tempat tumbuh yang kurang mendukung pertumbuhan tanaman A. mangium. Hal ini terlihat pada hasil analisis tanah pada Blok M1W yang menunjukkan bahwa $\mathrm{pH}$ yang masam, KTK dan kandungan unsur hara seperti $\mathrm{N}$, P, dan $\mathrm{K}$ yang rendah, dan kandungan logam berat yaitu $\mathrm{Al}$ cukup tinggi (Tabel 2). Pembahasan di atas telah menggambarkan bahwa kondisi tempat tumbuh di lokasi penelitian menunjukkan kondisi tanah yang kurang mendukung pertumbuhan tanaman A. mangium sehingga perlu banyak perbaikan. Tanaman A. mangium termasuk ke dalam jenis tanaman yang dapat tumbuh pada areal miskin hara atau bersifat masam, tetapi pada kondisi tanah yang ekstrim tanaman A. mangium tidak dapat tumbuh dengan optimal (Putri 2012). Adanya genangan air di areal revegetasi, kondisi tanah yang padat, dan erosi tanah menyebabkan pertumbuhan tanaman A. mangium terganggu dan merupakan salah satu faktor penyebab kondisi tanah menjadi ekstrim.

Permasalahan tempat tumbuh pada plot pegamatan yang kurang mendukung pertumbuhan tanaman menjadi perhatian khusus pada penelitian ini. Menurut Setiadi (2012) menyatakan bahwa salah satu alternatif yang dapat dilakukan untuk memperbaiki pertumbuhan tanaman yaitu dengan pembenah tanah yang diikuti dengan penyulaman tanaman yang tahan terhadap kondisi tanah yang masam dan memiliki kandungan Al yang tinggi, antara lain jenis tembesu (Fragraea fragrans). Tanaman ini diharapkan akan membantu dalam kegiatan revegetasi pada lahan pasca tambang yang memiliki kondisi tanah yang sangat beragam dan mengandung logam berat yang tinggi. Selain itu, upaya perbaikan yang telah dilakukan oleh perusahaan diantaranya pada kondisi tanah yang masam dapat diperbaiki dengan pengapuran, KTK yang rendah diperbaiki dengan penambahan bahan organik, fraksi pasir yang mendominasi pada plot pengamatan dapat diganti dengan tanaman lain yang lebih tahan pada tanah berpasir seperti belangeran (Shorea belangeran), adanya genangan air juga dapat ditanami dengan jenis kayu putih (Melaleuca leucadendron) yang adaptif terhadap adanya genangan air (Nurhayati et al. 2014).

Kegiatan pemeliharaan setelah penanaman juga merupakan salah satu faktor penting dalam melaksanakan kegiatan revegetasi. Tanaman $A$. mangium memerlukan pemeliharaan yang lebih intensif pada usia muda agar dapat tumbuh dengan optimal. Jenis A. mangium di lokasi penelitian sebagian besar 
memiliki percabangan yang banyak karena di tanam pada lahan terbuka. Menurut Krisnawati et al. (2011) pemangkasan cabang perlu dilakukan pada awal pertumbuhan tanaman karena tanaman A. mangium memiliki kemampuan meluruhkan cabangnya yang kurang. Pemangkasan cabang sebaiknya dilakukan pada umur 1 tahun setelah tanam dan pemangkasan berikutnya dilakukan pada tahun kedua sebelum mencapai ketiggian $2-3 \mathrm{~m}$ serta tahun ketiga sebelum mencapai ketinggian $5 \mathrm{~m}$ dan diameter batang $2 \mathrm{~cm}$ untuk menghindari infeksi jamur terutama busuk hati (Srivastava 1993). Selain percabangan yang banyak pada tanaman A. mangium di lokasi penelitian juga tanaman ini memiliki anakan alam yang banyak yang tumbuh disekitarnya sehingga tanaman relatif tumbuh dengan rapat dan persaingan unsur hara di dalamnya akan meningkat. Tujuan dari penanaman di areal revegetasi PT JBG ini adalah mengembalikan ke kondisi awal dimana harus terdapat jenis tanaman lokal setempat yang ditanam pada lokasi areal yang direklamasi. Oleh karena itu perlu dilakukannya penjarangan untuk memberi ruang bagi jenis tanaman lokal yang akan ditanam. Menurut Krinawati et al. (2007) menyatakan bahwa kebutuhan penjarangan bervariasi tergantung pada kerapatan tegakan dan kualitas tempat tumbuhnya, hasil penelitiannya menyarankan bahwa penjarangan pertama sebaiknya dilakukan pada umur $2-4$ tahun.

Pengendalian hama dan penyakit pada areal revegetasi PT JBG masih belum diterapkan. Standar Operasional Prosedur untuk kegitan pemeliharaan hanya tercantum tiga kegiatan yaitu pemupukkan, penyiangan, dan penyulaman. Hasil pengamatan di lapangan menunjukkan bahwa serangan hama dan penyakit cukup tinggi terutama pada plot pengamatan yang hampir mendekati $50 \%$. Hal ini dapat menyebabkan rendahnya performa tanaman dan mengurangi tingkat keberhasilan revegetasi. SOP mengenai pengendalian hama dan penyakit dibutuhkan untuk mengatasi permasalahan tersebut sehingga keberhasilan revegetasi dapat sesuai dengan yang diharapkan.

Perbaikan tanaman di lokasi penelitian perlu difokuskan berdasarkan hasil evaluasi keberhasilan revegetasi yang telah dilakukan agar rekomendasi yang diberikan bisa sesuai yang diharapkan. Hasil evaluasi keberhasilan revegetasi pada penelitian ini ditemukan beberapa plot contoh pengamatan yang harus diperhatikan kaitannya dengan pertumbuhan tanaman yang masih kurang baik dan bahkan masih buruk. Plot 9 dan 14 memiliki kondisi pertumbuhan tanaman yang buruk sehingga pada plot tersebut perlu diperbaiki terlebih dahulu agar pertumbuhan tanaman di plot tersebut tidak tertinggal jauh dari plot-plot lain yang kondisi pertumbuhannya lebih baik.

\section{SIMPULAN DAN SARAN}

\section{Simpulan}

Kondisi pertumbuhan tanaman revegetasi $A$. mangium pada Blok M1W PT Jorong Barutama Greston dapat dikatakan belum berhasil dilihat dari rata-rata persentase tumbuh dan persentase kesehatan tanaman yang masih berada dalam kategori tumbuh tidak baik (nilai skor 1untuk kedua kriteria pertumbuhan tanaman tersebut). Perbaikan yang dapat dilakukan di lokasi penelitian adalah melakukan pembenah tanah yang diikuti dengan penyulaman menggunakan tanaman yang tahan terhadap tanah masam dan kandungan logam berat yang tinggi. Penyebab utama ketidakberhasilan revegetasi dikarenakan kondisi tempat tumbuh yang kurang mendukung pertumbuhan tanaman A. mangium dan kurangnya pemeliharaan tanaman. Hal tersebut menjadi penyebab menurunnya keberhasilan tanaman revegetasi. Selain itu, Standar Operasional Prosedur (SOP) kegiatan revegetasi perlu diperbaiki dengan penambahan mengenai kegiatan pemeliharaan tanaman kaitannya dengan pengendalian hama dan penyakit.

\section{Saran}

Rekomendasi yang dapat diberikan dalam hasil penelitian yaitu perlu adanya klasifikasi mengenai karateristik lahan terlebih dahulu agar mengetahui permasalahannya dan dapat menentukan perbaikan tanah yang tepat untuk mencegah ketidakberhasilan revegetasi; melakukan analisis tanah pada lahan yang akan direvegetasi sebelum penanaman agar diketahui pembenah tanah yang tepat sehingga kondisi tanah pada saat penanaman sudah mendukung bagi pertumbuhan tanaman; dan kegiatan pemeliharaan tanaman sebaiknya dilakukan secara teratur dalam jangka waktu tertentu agar pertumbuhan dan kesehatan tanaman revegetasi dapat tumbuh dengan optimal serta Standar Operasional Prosedur (SOP) mengenai kegiatan revegetasi perlu diterapkan sesuai ketentuan dan perlu adanya pengawasan yang lebih intensif saat kegiatan revegetasi tersebut dilakukan.

\section{DAFTAR PUSTAKA}

Adinda. 2012. Evaluasi pertumbuhan pohon di lokasi revegetasi lahan pasca tambang PT. Vale Indonesia Tbk, Sorowako, Sulawesi Selatan [skripsi]. Bogor (ID): Institut Pertanian Bogor.

Adinugroho WC. 2010. Analisa Permenhut No.P.60/Menhut-II/2009 tentang Pedoman Penilaian Keberhasilan Reklamasi Hutan [Internet]. [Waktu dan tempat tidak diketahui]. Jakarta (ID): hlm 1 - 5; [diunduh 2015 Apr 6]. Tersedia pada: https://wahyukdephut.files.wordpress.com/2010/02/a nalisa-permenhut-pedoman-penilaian-keberhasilanreklamasi-hutan.pdf

[Kemenhut] Kementerian Kehutanan. 2009. Peraturan Menteri Kehutanan Republik Indonesia Nomor: P.60/Menhut-II/2009 tentang Pedoman Penilaian Keberhasilan Reklamasi Hutan. Jakarta (ID): Kemenhut.

[Kemenhut] Kementerian Kehutanan. 2011. Peraturan Menteri Kehutanan Republik Indonesia Nomor: P.04/Menhut-II/2011 tentang Pedoman Reklamasi Hutan. Jakarta (ID): Kemenhut.

Hardjowigeno S. 2007. Ilmu Tanah. Ed ke-7. Jakarta (ID): Akademika Pressindo.

Indriyanto. 2008. Ekologi Hutan. Ed ke-2. Jakarta (ID): PT. Bumi Aksara. 
Indriyanto. 2008. Pengantar Budidaya Hutan. Jakarta (ID): PT. Bumi Aksara.

Krisnawati H, Kallio M, Kanninen M. 2011. Acacia mangium Willd. Ekologi, Silvikultur dan Produktivitas. Bogor (ID): CIFOR.

Lakitan B. 2007. Dasar-Dasar Fisiologi Tumbuhan. Jakarta (ID): PT. Raja Grafindo.

Mansur I. 2010. Teknik Silvikultur untuk Reklamasi Lahan Bekas Tambang. Bogor (ID): Seameo Biotrop.

Maryani IS. 2007. Dampak penambangan pasir pada lahan hutan alam terhadap sifat fisik, kimia, dan biologi tanah (Studi Kasus di Pulau Sebaik Kabupaten Karimun Kepulauan Riau) [skripsi]. Bogor (ID): Institut Pertanian Bogor.

Megawati NJ. 2014. Respon pertumbuhan Acacia mangium Willd. terhadap penambahan kapur dan HSC (Humic Subtances Complex) pada lahan pasca tambang batu bara [tesis]. Bogor (ID): Institut Pertanian Bogor.

Munawar A. 2011. Kesuburan Tanah dan Nutrisi Tanaman. Bogor (ID): IPB Press.

Nurhayati, Razali, Zuraida. 2014. Peranan berbagai jenis bahan pembenah tanah terhadap status hara $p$ dan perkembangan akar kedelai pada tanah gambut asal ajamu sumatera utara. Jurnal Floratek (9): 29 38. Universitas Syiah Kuala.

Putri AD. 2012. Evaluasi keberhasilan revegetasi tanaman hasil revegetasi di lahan pasca tambang batu bara Site Lati PT. Berau Coal Kalimantan Timur [skripsi]. Bogor (ID): Institut Pertanian Bogor.

Setiadi Y. 2006. Bahan Kuliah Ekologi Restorasi. Program Studi Ilmu Pengetahuan Kehutanan, Sekolah Pasca Sarjana, IPB. Tidak Diterbitkan.

Setiadi Y. 2011. Revegetasi Lahan Pasca Tambang. Diktat Kuliah Pengantar Parktek Kerja Lapang. Bogor (ID): Fakultas Kehutanan Institut Pertanian Bogor.

Setiadi Y. 2012. Pembenahan Lahan Pasca Tambang (Soil Amendment Post Mined Land). Post Mining Restoration Technical Note. Tidak Diterbitkan

Srivastava PBI. 1993. Silvicultural practice. dalam: Awang K dan Taylor D (ed) Acacia mangium: growing and utilization, 113-148. Winrock International dan Food and Agriculture Organization of the United Nations, Bangkok, Thailand 